Proceedings

\title{
Deploying Nanoparticle-Doped Polymeric Membranes in Treating Water Contaminated with Ciprofloxacin ${ }^{\dagger}$
}

\author{
Hebatullah H. Farghal *, Dina M. Hassanein, Aya Attia, Nahed Yacoub, Tarek Madkour and \\ Mayyada M.H. El-Sayed *
}

Department of Chemistry, School of Science and Engineering, The American University in Cairo, Cairo 11835, Egypt; dina_h1992@aucegypt.edu (D.M.H.); ayaattia@aucegypt.edu (A.A.); nahedy@aucegypt.edu (N.Y.); tarekmadkour@aucegypt.edu (T.M.)

* Correspondence: hebatullahfarghal@aucegypt.edu (H.H.F.); mayyada@aucegypt.edu (M.M.H.E.-S)

+ Presented at 1st International Electronic Conference on Applied Sciences, 10-30 November 2020; Available online: https://asec2020.sciforum.net/.

Published: 10 November 2020

\begin{abstract}
The antibiotic Ciprofloxacin $\mathrm{HCl}(\mathrm{CPH})$ is a representative example of pharmaceutical contaminants of emerging concern which are frequently released in wastewater effluents and can cause hazardous health effects. In this work, we investigate the potential of utilizing porous polymeric membranes incorporating metal nanoparticles for removing $\mathrm{CPH}$ from water. In this regard, polylactic acid/polyurethane membranes were impregnated in situ with single, binary and tertiary systems of nanoparticles of cobalt, copper and nickel, among others. Membranes loaded with cobalt exhibited the best performance among all the examined membranes. They yielded removal efficiencies above $80 \%$ at an initial $\mathrm{CPH}$ concentration range of $10-50 \mathrm{ppm}$ and $\mathrm{pH} 6.5$, thus exceeding those of the bare membranes by about 1.3 times under the same conditions. As confirmed by Brunauer, Emmet and Teller (BET) analysis, the incorporation of cobalt nanoparticles into the mesoporous membranes increased their surface area and pore volume by 5 and 10 times, respectively. Thermogravimetric analysis (TGA) showed that cobalt nanoparticles had no catalytic influence on the dissociation of the membrane polymeric chains. Fourier Transform Infra-red (FTIR) and zeta potential measurements suggested that binding could possibly occur via physical interactions along with catalytic degradation.
\end{abstract}

Keywords: Ciprofloxacin $\mathrm{HCl}$; nanoparticles; porous polymeric membranes; contaminants of emerging concern

\section{Introduction}

In recent years, there has been an increased human consumption of chemicals such as pharmaceuticals, personal care products, industrial chemicals, disinfectants and pesticides, among others. When released in water streams, even in minute amounts, these compounds can pass to the soil and ground water and then to the surface water which human and animals consume [1,2]. Without applying the proper water treatment methods, they will accumulate in the environment posing major health effects over prolonged periods of time [1]. Thus, they are referred to as "contaminants of emerging concern" or CECs since they have been often overlooked in the past with regard to their detection and treatment; however they recently gained much attention [3].

One of the CECs commonly found in wastewater is the pharmaceutical Ciprofloxacin $\mathrm{HCl}(\mathrm{CPH})$ that belongs to the fluoroquinolone group of antibiotics. It is active against gram-positive and gram- 
negative bacteria and performs its activity by inhibiting the enzyme catalytic activity involved in the bacterial nucleic acid synthesis [4]. The antibiotic was detected, at the microgram scale concentration, in various water streams including hospital effluents, sewage treatment plants' influents and effluents, as well as in drinking water [4]. It was also detected in maize tissue that had been irrigated with water containing the antibiotic, thus leading to possible bacterial resistance [5]. The presence of $\mathrm{CPH}$ in water leads to potential ecotoxicity to the heterobacteria Pseudomonas fluorescens at EC50 of $0.175 \mu \mathrm{g} / \mathrm{L}$, reduced growth of the mycrophyte phragmitis australis at a concentration of $2 \mathrm{mg} / \mathrm{L}$ after 5 days and increased length and weight of the fish Cyprinus carpio in its early stages at a concentration of $1 \mathrm{mg} / \mathrm{L}$ [6]. It was confirmed that CPH is a persistent drug in wastewater which cannot be removed efficiently with conventional water treatment methods such as biological degradation and flocculation [7].

Several approaches have been investigated for the removal of $\mathrm{CPH}$ from wastewater including reverse osmosis, advanced oxidation processes and adsorptive removal [8-10]. One recently adopted method involved the use of metal nanoparticles due to their catalytic activity beside their sorptive properties [11,12]. In this work, we investigate the potential of removing $\mathrm{CPH}$ using metal nanoparticles incorporated into a polymeric porous membrane of the biopolymer blend, polylactic acid/polyurethane. This approach addresses the challenges associated with one or more of the previously reported materials by providing environmentally-friendly, high surface area nanoporous membranes that can be deployed within a low-energy process that does not require high pressure demands as encountered with the regular sorption polymeric systems [13]. It can also mitigate the possible toxicity arising from the release of free metal nanoparticles in water [14].

\section{Materials and Methods}

\subsection{Materials and Chemicals}

Ciprofloxacin $\mathrm{HCl}$ was brought from EIPICO Pharmaceuticals, Sharqia Governorate, Egypt. Polylactic acid (PLA) of density $1.24 \mathrm{~g} / \mathrm{cm}^{3}$ was purchased from Nature Works, Minnetonka, Minnesota, USA under the code name 4060D, while polyester-based polyurethane (PU) pellets with the commercial name "polyurethane" of density $1.21 \mathrm{~g} / \mathrm{cm}^{3}$ were obtained from Alfa Aesar (Kandel, Germany). As for metal precursors and reducing agents, sodium chloride was purchased from Alfa Aesar (Kandel, Germany), while cobalt chloride hexahydrate, anhydrous copper chloride, nickel chloride hexahydrate and sodium borohydride were purchased from Loba Chemie, Maharashtra, India. Solvents, such as $N, N$ dimethyl-formamide $(\leq 99 \%)$, absolute ethanol (anhydrous) and 1,4dioxane were purchased from Fisher Chemical Company (Hampton, VA, USA).

\subsection{In-Situ Preparation of Metal Loaded Porous Membranes}

The nanoporous membranes were prepared using the solvent casting technique with a mixture of PLA and PU as described in [15], with $10 \%$ cellulose acetate (CA) and $50 \% \mathrm{NaCl}$ crystals (pore formers). They were then soaked in $0.1 \mathrm{M}$ of the metal salt solution for 3 days on an orbital shaker, then added to a $0.5 \mathrm{M} \mathrm{NaBH}_{4}$ aqueous solution and kept shaking for $24 \mathrm{~h}$ on an orbital shaker at room temperature to allow all the metal salt ions to be reduced to metal nanoparticles.

\subsection{Characterization}

Fourier Transform Infra-Red (FTIR) spectroscopy measurements were performed for the prepared membranes before and after adsorption using the $\mathrm{KBr}$ disc method in the range of 400-4000 $\mathrm{cm}^{-1}$. Dynamic light scattering (DLS) measurements were performed to determine the zeta potential of the membranes before and after adsorption. Scanning electron microscopy (SEM) and Brunauer, Emmett and Teller (BET) measurements were also performed to determine the morphology and surface characteristics of the membranes, while Thermogravimetric analysis (TGA) was applied to investigate their thermal stability.

\subsection{Adsorption Experiments}


Cut membranes of dimensions $1^{*} 2 \mathrm{~cm}^{2}$ and predetermined weight were added to $15 \mathrm{~mL}$ of $\mathrm{CPH}$ solutions of concentrations $(2.5,5,10,25$, and $50 \mathrm{ppm})$ into $15-\mathrm{mL}$ falcon tubes. They were then left on a shaker in the dark, at room temperature and $\mathrm{pH}$ 6.5. The adsorption experiment was halted after 8h. Afterward, the absorbance of CPH was determined using a UV/Vis spectrophotometer at $286 \mathrm{~nm}$ wavelength and the corresponding concentration of $\mathrm{CPH}$ was then calculated from a pre-prepared calibration curve. Percent removal and adsorption capacity were determined from the following equations:

$$
\begin{gathered}
\% \text { Removal }=\frac{\boldsymbol{c}_{\mathrm{i}}-\boldsymbol{c}_{\mathrm{e}}}{\boldsymbol{c}_{\mathrm{i}}}, \\
q_{e}=\frac{\left(\boldsymbol{c}_{\mathrm{i}}-\boldsymbol{c}_{\mathrm{e}}\right) \boldsymbol{V}}{X}
\end{gathered}
$$

where $C_{\mathrm{i}}$ is the initial $\mathrm{CPH}$ concentration, $C_{\mathrm{e}}$ is the equilibrium concentration, $q_{\mathrm{e}}$ is the equilibrium adsorption capacity, $V$ is the total volume of the solution in the falcon tube, and $X$ is the dry mass or surface area of the cut membranes.

\section{Results and Discussion}

\subsection{Screening of the \%Removal of Several Metal Loaded Polymeric Membranes}

Initially, a screening study was performed to identify the most efficient membranes with regard to their removal for $\mathrm{CPH}$. Fourteen different membranes were examined, non-porous polymeric membrane which was prepared in absence of $\mathrm{NaCl}(\mathrm{np})$, porous polymeric membrane (p), and porous polymeric membranes loaded with $\mathrm{Co}, \mathrm{Ni}, \mathrm{Cu}, \mathrm{ZnO}, \mathrm{TiO}_{2}, \mathrm{WO}_{3}, \mathrm{Fe}_{2} \mathrm{O}_{3}$, graphene oxide (GO), $\mathrm{Fe} / \mathrm{Co}, \mathrm{Fe} / \mathrm{Ni}, \mathrm{Ni} / \mathrm{Co}$, or $\mathrm{Fe} / \mathrm{Co} / \mathrm{Ni}$. The removal efficiencies of these membranes (Figure 1a) were obtained after $8 \mathrm{~h}$ of adsorption using $50 \mathrm{ppm}$ of $\mathrm{CPH}$. Clearly, the cobalt-loaded membranes exhibited the highest removal efficiency of $80.7 \%$, followed by the copper-loaded ones $(70.9 \%)$ then the nickel-loaded ones (68.8\%). On the other hand, the bare porous ( $\mathrm{p}$ ) and non-porous membranes (np) yielded comparable efficiencies of $61.8 \%$ and $61.9 \%$, respectively implying that the removal is independent on porosity. This may suggest that the mechanism of adsorption is mainly governed by surface interactions rather than pore diffusion. Having lower efficiencies than those of cobalt-loaded, copper-loaded or nickel-loaded membranes suggests that the nanoparticles contribute to the adsorption. Meanwhile, titanium dioxide, ferric oxide, zinc oxide, GO and $\mathrm{WO}_{3}$ loaded membranes showed removal efficiencies that ranged from $40 \%$ to $52 \%$. Interestingly, utilizing binary or tertiary nanoparticle mixtures of $\mathrm{Co}$ or $\mathrm{Ni}$ with other metals reduced the removal efficiency relative to that of the single component nanoparticles of $\mathrm{Co}$ or $\mathrm{Ni}$, showing the lowest recorded removal efficiencies among all the deployed membranes (7-22\%). This antagonistic effect could be owed to possible interaction between the components of the mixture [16].

Since $\mathrm{Co}, \mathrm{Cu}, \mathrm{Ni}$-loaded membranes showed the best removal, we focused on studying their removal efficiencies and adsorption capacities over a range of different initial $\mathrm{CPH}$ concentrations (Figure 1b-d). As depicted in Figure 1b, the removal efficency slightly increases with increasing the concentration in the range of $5-50 \mathrm{ppm}$, then remains almost constant in the range of 10-50 ppm indicating saturation of adsorption sites. Similar trend was observed in previous literature where 3.6100 ppm methylene blue was biosorbed on fava bean peels [17]. The corresponding equilibrium adsorption capacities were then calculated per unit area or dry mass of the membrane as shown in Figure 1c,d, respectively. A clear linear correlation can be realized between the adsorption capacity and the initial $\mathrm{CPH}$ concentration. The adsorption capacity increases proportionally with concentration probably due to a decrease in the mass transfer resistance resulting from the higher concentration gradient as previously reported [18]. Adsorption capacities of 37, 33 and $32 \mathrm{mg} / \mathrm{g}$ corresponding to 3027, 2660 and $2578 \mathrm{mg} / \mathrm{m}^{2}$, for Co, Cu and Ni-loaded membranes, respectively were obtained at $50 \mathrm{ppm}$ of $\mathrm{CPH}$, as opposed to $29 \mathrm{mg} / \mathrm{g}\left(2324 \mathrm{mg} / \mathrm{m}^{2}\right)$ and $28 \mathrm{mg} / \mathrm{g}\left(2317 \mathrm{mg} / \mathrm{m}^{2}\right)$ pertaining to non-porous and porous membranes, respectively. Given that cobalt-loaded membranes 
showed the best performance probably due to the highest catalytic activity of Co nanoparticles relative to the other investigated nanoparticles, it will be the focus of the following characterization studies.
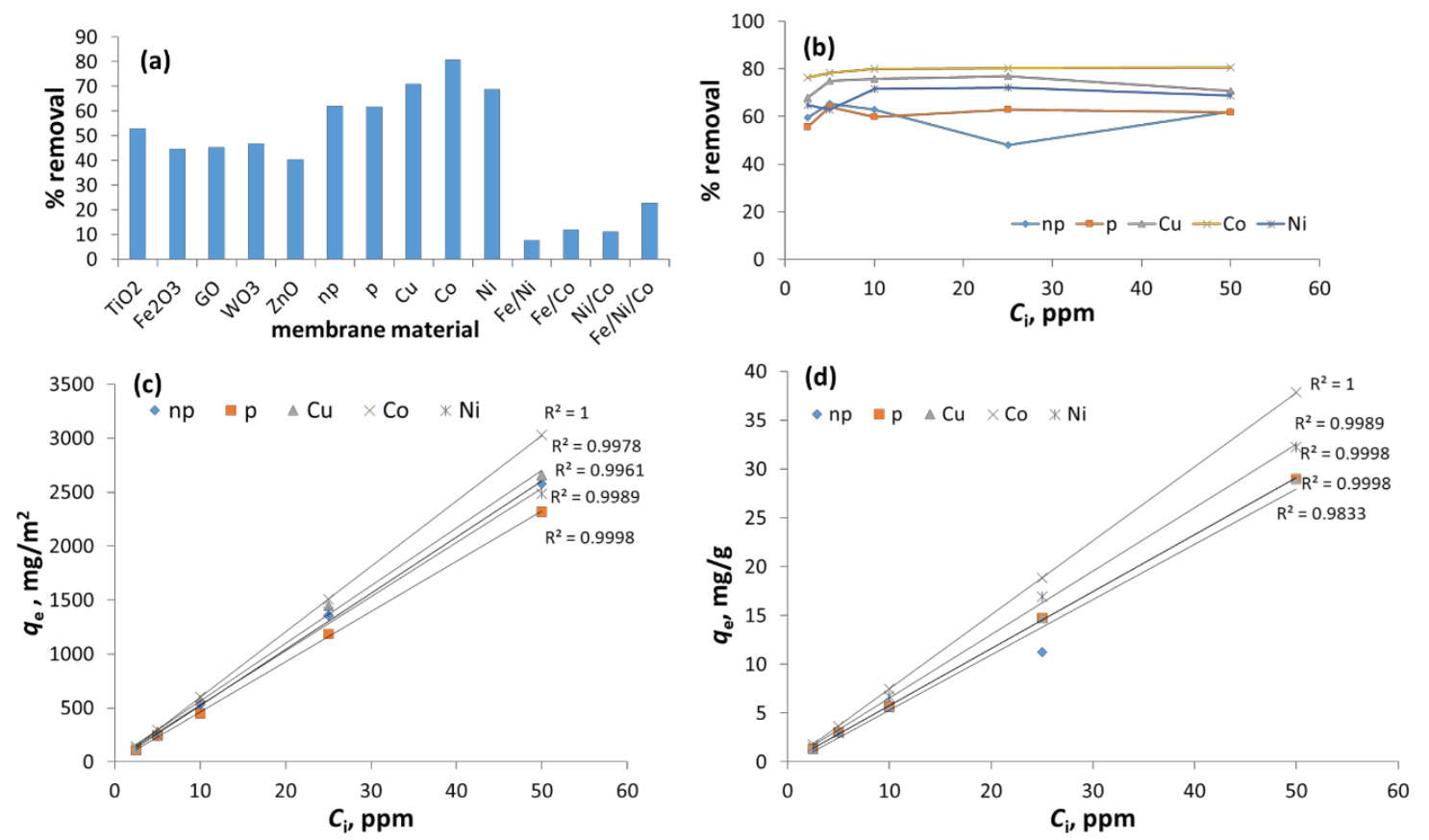

Figure 1. (a) Percentage removal of $\mathrm{CPH}$ using various metal loaded polymeric membranes, at an initial CPH concentration of $50 \mathrm{ppm}$ and $\mathrm{pH}$ 6.5, (b) Percentage removal of different concentrations of $\mathrm{CPH}$ using the most efficient employed membranes, (c) equilibrium adsorption capacity in $\mathrm{m}^{2} / \mathrm{g}$ and (d) equilibrium adsorption capacity in $\mathrm{mg} / \mathrm{g}$ onto the most efficient employed membranes.

\subsection{Characterization of Membranes}

\subsubsection{FTIR and DLS Measurements}

DLS measurements showed that cobalt-loaded membranes maintained its neutrality after adsorption which suggests that it bound with $\mathrm{CPH}$ through physical interactions and possibly catalytic degradation. This is supported by the FTIR measurements (Figure 2) for this membrane where almost no apparent shift in peak energies for $\mathrm{CH} s p^{2}$ alkene, $\mathrm{CH} s p^{3}$ alkane and $\mathrm{C}=\mathrm{O}$ was observed before and after adsorption. Besides, the disappearance of some of the peaks typical of $\mathrm{CPH}$ may be likely a result of the catalytic degradation.

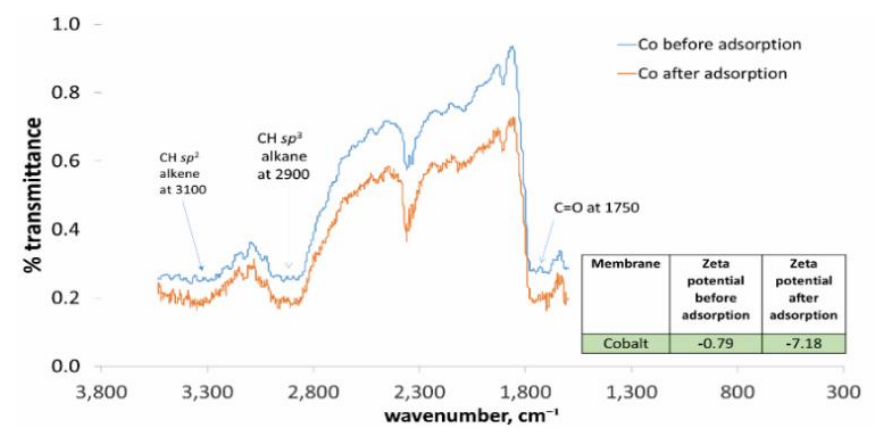

Figure 2. FTIR spectra and zeta potential values for Co-loaded membranes before and after adsorption.

\subsubsection{SEM Measurements}


The SEM images, shown in Figure 3, reveal the porous structure of the unloaded membranes; while the cobalt-loaded ones possess a rough surface owing to the impregnated cobalt nanoparticles.
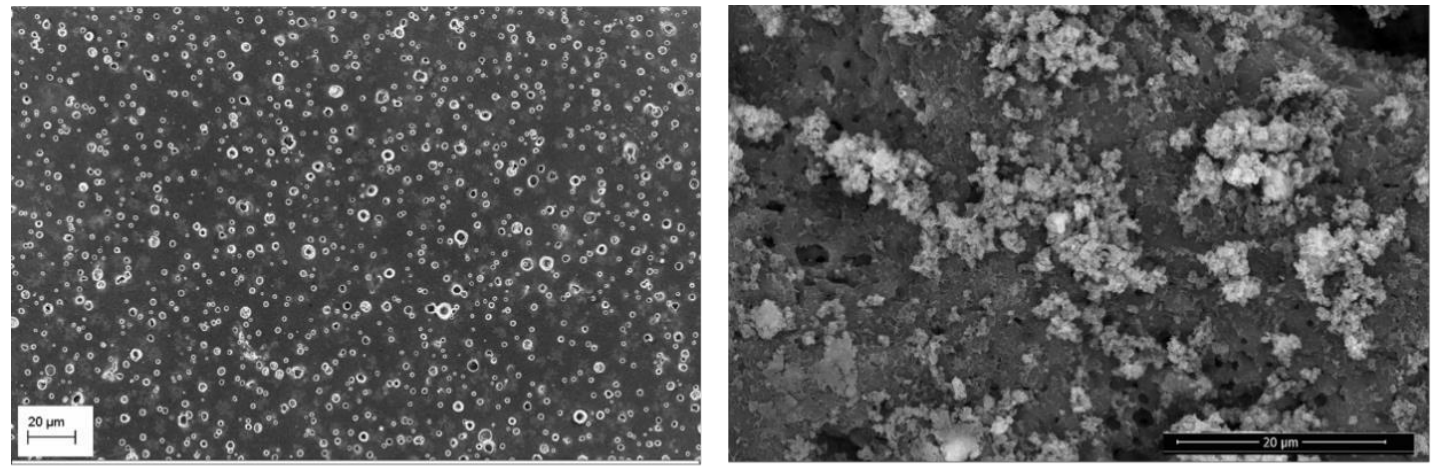

Figure 3. SEM images for unloaded porous membranes (left panel), and Co-loaded membranes (right panel).

\subsubsection{TGA and BET Measurements}

The TGA profiles in Figure 4 (left panel) show a two-step degradation mechanism with no apparent temperature shifts between the unloaded and cobalt-loaded membranes, implying that the nanoparticles had no catalytic influence on the degradation of the polymer chains. BET isotherms in Figure 4 (right panel) confirm a mesoporous structure with pore sizes ranging from 2 to $50 \mathrm{~nm}$ where surface area and pore volume for Co-loaded membranes $\left(0.399 \mathrm{~m}^{2} / \mathrm{g}\right.$ and $\left.0.002 \mathrm{~cm}^{3} / \mathrm{g}\right)$ were $5-10$ times larger than those of the unloaded ones $\left(0.083 \mathrm{~m}^{2} / \mathrm{g}\right.$ and $\left.0.0002 \mathrm{~cm}^{3} / \mathrm{g}\right)$.
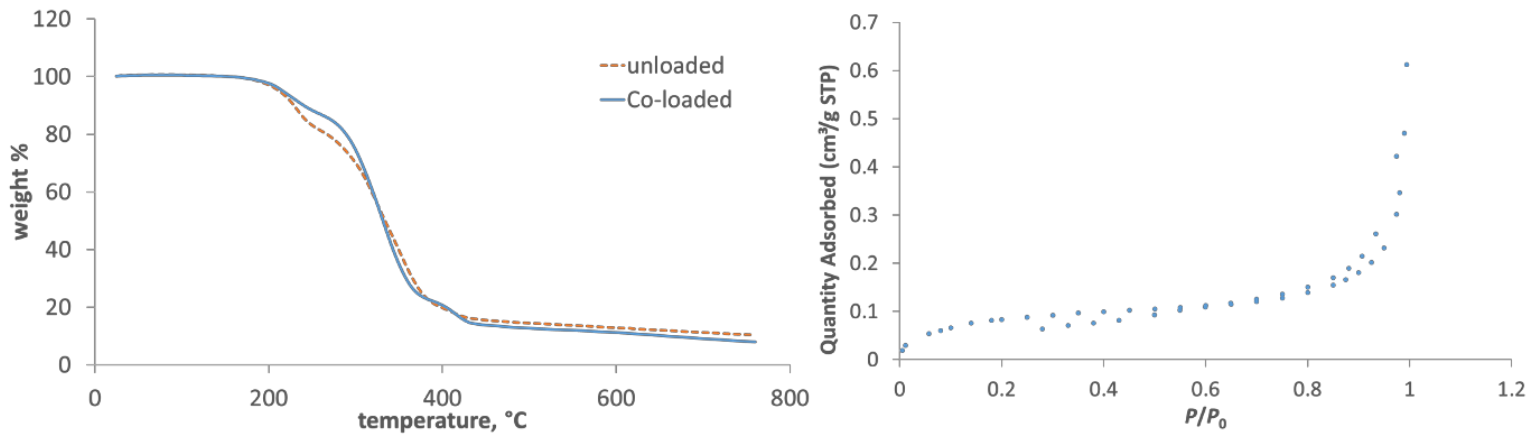

Figure 4. TGA for unloaded and cobalt-loaded membranes (left panel), and BET for cobalt-loaded membranes (right panel).

\section{Conclusions}

Cobalt-loaded mesoporous membranes successfully removed CPH from aqueous solutions with an efficiency of more than $80 \%$. FTIR and zeta potential measurements suggest that binding took place through physical interactions and catalytic degradation mechanisms.

Author Contributions: adsorption experiments and writing original draft preparation, H.H.F.; FTIR and DLS measurements, D.M.H.; membrane preparation, SEM and TGA, A.A.; BET, N.Y.; supervision, T.M.; supervision and revision, M.M.H.E.-S. All authors have read and agreed to the published version of the manuscript.

Funding and Acknowledgments: We would like to acknowledge The American University in Cairo that supported the completion of this work through research grants number RSG2-19.

Conflicts of Interest: The authors declare no conflict of interest. The funders had no role in the design of the study; in the collection, analyses, or interpretation of data; in the writing of the manuscript, or in the decision to publish the results.

\section{References}


1. Nawaz, T.; Sengupta, S. Contaminants of Emerging Concern: Occurrence, Fate, and Remediation. In Advances in Water Purification Techniques; Elsevier: Amsterdam, The Netherlands, 2019; pp. 67-114.

2. Li, W.C. Occurrence, sources, and fate of pharmaceuticals in aquatic environment and soil. Environ. Pollut. 2014, 187, 193-201.

3. Sciex. Contaminants of Emerging Concern. Available online: https://sciex.com/applications/environmentaltesting/contaminants-of-emerging-concern (accessed on 21 October 2020).

4. de Lima Perini, J.A.; Perez-Moya, M.; Nogueira, R.F.P. Photo-Fenton degradation kinetics of low ciprofloxacin concentration using different iron sources and pH. J. Photochem. Photobiol. A Chem. 2013, 259, 53-58.

5. Gomes, M.P.; Rocha, D.C.; de Brito, J.C.M.; Tavares, D.S.; Marques, R.Z.; Soffiatti, P.; Sant'Anna-Santos, B.F. Emerging contaminants in water used for maize irrigation: Economic and food safety losses associated with ciprofloxacin and glyphosate. Ecotoxicol. Environ. Saf. 2020, 196, 110549.

6. Sahlin, S.; Joakim Larsson, D.G.; Ågerstrand, M. Ciprofloxacin: EQS Data Overview; ACES Report 15; The Department of Environmental Science and Analytical Chemistry (ACES): Stockholm, Sweden, 2018.

7. Frade, V.M.F.; Dias, M.; Teixeira, A.C.S.C.; Palma, M.S.A. Environmental contamination by fluoroquinolones. Braz. J. Pharm. Sci. 2014, 50,41-54.

8. Fei, Y.; Li, Y.; Han, S.; Ma, J. Adsorptive removal of ciprofloxacin by sodium alginate/graphene oxide composite beads from aqueous solution. J. Colloid Interface Sci. 2016, 484, 196-204.

9. Mondal, S.K.; Saha, A.K.; Sinha, A. Removal of ciprofloxacin using modified advanced oxidation processes: kinetics, pathways and process optimization. J. Clean. Prod. 2018, 171, 1203-1214.

10. Alonso, J.J.S.; El Kori, N.; Melián-Martel, N.; Del Río-Gamero, B. Removal of ciprofloxacin from seawater by reverse osmosis. J. Environ. Manag. 2018, 217,337-345.

11. Rakshit, S.; Sarkar, D.; Elzinga, E.J.; Punamiya, P.; Datta, R. Mechanisms of ciprofloxacin removal by nanosized magnetite. J. Hazard. Mater. 2013, 246, 221-226.

12. Gan, Y.; Wei, Y.; Xiong, J.; Cheng, G. Impact of post-processing modes of precursor on adsorption and photocatalytic capability of mesoporous $\mathrm{TiO}_{2}$ nanocrystallite aggregates towards ciprofloxacin removal. Chem. Eng. J. 2018, 349, 1-16.

13. M'bareck, C.O.; Nguyen, Q.T.; Alexandre, S.; Zimmerlin, I. Fabrication of ion-exchange ultrafiltration membranes for water treatment: I. Semi-interpenetrating polymer networks of polysulfone and poly (acrylic acid). J. Membr. Sci. 2006, 278,10-18.

14. Ates, M.; Demir, V.; Arslan, Z.; Camas, M.; Celik, F. Toxicity of engineered nickel oxide and cobalt oxide nanoparticles to Artemia salina in seawater. Water Air Soil Pollut. 2016, 227, 70.

15. Ibrahim, A.H.; Zikry, A.A.; Azzam, R.A.; Madkour, T.M. Facile Synthesis of Novel Tough and Highly Flexible Biodegradable Membranes for Water Microfiltration. Adv. Mater. Lett. 2019, 10, 595-603.

16. Aslibeiki, B. Magnetic interactions and hysteresis loops study of $\mathrm{Co} / \mathrm{CoFe}_{2} \mathrm{O}_{4}$ nanoparticles. Ceram. Int 2016, 42, 6413-6421.

17. Bayomie, O.S.; Kandeel, H.; Shoeib, T.; Yang, H.; Youssef, N.; El-Sayed, M.M. Novel approach for effective removal of methylene blue dye from water using fava bean peel waste. Sci. Rep. 2020, 10, 1-10.

18. Mohammad, S.G. (The American University In Cairo, Cairo, Egypt); El-Sayed, M.M. (The American University In Cairo, Cairo, Egypt). Removal of imidacloprid pesticide using nanoporous activated carbons produced via pyrolysis of peach stone agricultural wastes. Chemical Engineering Communications, 2020.

Publisher's Note: MDPI stays neutral with regard to jurisdictional claims in published maps and institutional affiliations.

(C) 2020 by the authors. Licensee MDPI, Basel, Switzerland. This article is an open access article distributed under the terms and conditions of the Creative Commons Attribution (CC BY) license (http://creativecommons.org/licenses/by/4.0/). 